\title{
Antibacterial, Antidiabetic and Lipid Lowering Effects of Ethanolic Extract of Ipomoea aquatica
}

\author{
Chand Sultana Khatun ${ }^{1}$, Md. Ashraful Islam¹, Md. A. K. Azad ${ }^{1}$, Md. Ashraf Ali ${ }^{1}$, Md. Feroz Hassan ${ }^{1}$, Md. \\ Wahidunnobi ${ }^{1}$, Md Sohel Sabus Khan ${ }^{1}$, Khadiza Begum² and Kohinur Begum ${ }^{3 *}$ \\ ${ }^{1}$ Department of Pharmacy, Bangladesh University, Dhaka-1207, ${ }^{2}$ Department of Biochemistry, Ibrahim Medical College, Dhaka- 1000, ${ }^{3}$ Department of \\ Pharmacy, Primeasia University, Dhaka-1213
}

\begin{abstract}
Present study was designed to investigate antibacterial, antidiabetic and lipid lowering effects of ethanolic leaf extract of Ipomoea aquatica (IA). The antibacterial effect of IA leaf extract was performed using agar-cup-diffusion assay against six pathogenic bacterial strains such as Klebsiella aerogenes, Escherichia coli, Staphylococcus aureus and Bacillus cereus Vibrio cholerae and Salmonella typhi. This extract has potent antibacterial effect against all six strains compared to commercially available antibiotics of cetriaxone, ciprofloxacin and ampicillin. Total of 40 Swiss Albino male mice were used for investigation of antidiabetic and lipid lowering effects and made diabetic by alloxan. 20 mice were used for oral glucose tolerance test (OGTT) and 20 mice for a week-long anti-hyperglycemic. Both groups were subdivided into four, each having 5 mice- i) the control receive only $0.5 \%$ methyl cellulose as vehicle; ii) Standard received vehicle plus metformin; iii \& iv) test samples DIA 250 and DIA 500 received vehicle plus IA extract with 250 and $500 \mathrm{mg} / \mathrm{kg}$ b. wt (body weight), respectively. Lipid profile analysis was performed by estimating total cholesterol (TC), triglyceride (TG) and liver glycogen concentration on 20 mice after week-long antihyperglycemic tested mice. The glucose tolerance results showed significant $(p<0.05)$ and improved $50.03 \%$ and $66.09 \%$ at the DIA250 and DIA500, respectively. However, IA significantly reduced $(p<0.05)$ blood glucose level $57.89 \%$ and $69.12 \%$ at the DIA250 and DIA500, respectively for a weeklong anti-hyperglycemic activity. Both glucose tolerance and hypoglycemic effect is comparable to diabetic control group and the effect is dose dependent. In addition to anti-hyperglycemic effect, alloxan induced diabetic mice showed increase in plasma TC and TG level. After the administration of IA extract, TC and TG level were restored to near normal level which showed significant $(\mathbf{p}<0.05)$ results. The results of IA extract also showed significant $(\mathbf{p}<0.05)$ and improved liver glycogen content compared to diabetic control mice group. These results indicate that IA has antibacterial, antidiabetic and lipid lowering effects.
\end{abstract}

Key words: Ipomoea aquatica (IA), antibiotic, Oral Glucose Tolerance Test (OGTT), Total Cholesterol (TC), Triglyceride (TG), Liver glycogen.

\section{Introduction}

Peoples of rural areas use different plant parts for various ailments. In recent years, there has been a resurgence of scientific interest in the use of medicinal plants for the development of new pharmacotherapeutic agents against different diseases. Ipomoea aquatica Forsk. (IA) belonging to the family Convolvuleceae, commonly known as kalmi sag or water spinach. It is cultivated throughout Southeast Asia and is widely consumed vegetable in the region. IA contains several vitamins including $\mathrm{A}, \mathrm{B}, \mathrm{C}$ and $\mathrm{E}$, used to treat gastric and intestinal disorders ${ }^{1}$. The species also contains aliphatic pyrrolidine amides, carotenoids, hentriacontane, ß-sitosterol and glycosides, prostaglandin, leukotrine, $\mathrm{N}$-trans- and $\mathrm{N}$-cis feruloyltyramines ${ }^{2-6}$. Only a very few scientific studies have been conducted on its medical aspects. These include the effects on liver diseases ${ }^{7}$ and constipation ${ }^{8}$. Water spinach is also supposed to possess insulin like activity according to indigenous in Srilanka ${ }^{9}$. Medicinal properties of this plant has been used in nosebleed and high blood pressure ${ }^{10,11}$. However, there is little information available about the antimicrobial activity of this plant. In the light from the literature, this study has been designed to investigate antibacterial, antihyperglycemic and lipid lowering potentials of Ipomoea aquatica.

\section{Materials and Methods}

\section{Preparation of extract}

Fresh leaves of IA were collected from Savar, Dhaka in October, 2010 and the plant authenticity was confirmed from the Bangladesh National Herbarium, Mirpur, Dhaka. The collected leaves were washed and sun dried under shadow for one week. Dried leaves were powered by electric grinder. The powdered plant leaves were extracted with $95 \%$ ethanol at room temperature. The bottle were kept at room temperature and allowed to stand for 7-10 days with occasional shaking and

*Corresponding Author:

Dr. Kohinur Begum, Professor and Head, Department of Pharmacy, Primeasia University, Dhaka-1213, E.mail: kohinur025@yahoo.com. 
stirring. Ethanolic extracts is obtained by filtration using filter paper. The filtrate was defatted with petroleum ether. Defatted liquor was concentrated by evaporation using rotary evaporator at temperature $40-45^{\circ} \mathrm{C}$.

\section{Antibacterial assay}

The antibacterial potentialities of plant extracts were evaluated by agar cup diffusion method using Mueller Hinton agar medium against six pathogenic bacterial strains including Escherichia coli, Pseudomonas aeruginosa, Vibrio cholerae, Salmonella typhi, Staphylococcus aureus and Bacillus cereus. The diluted extract $(150 \mu \mathrm{g} / 100 \mu \mathrm{l})$ was dispended into in each cup $(4 \mathrm{~mm}$ diameter) of the bacterium seeded agar plate and commercial available ampicillin $(20 \mu \mathrm{g})$, ceftriaxone $(30 \mu \mathrm{g})$ and ciprofloxacin $(5 \mu \mathrm{g})$ antibiotic discs were used for comparative study. Antimicrobial activity was assessed based on measurement of the diameter (mm) of the clear zone around the cup and each experiment was repeated three times and the mean diameter was taken.

Drugs and chemicals for antihyperglycemic and lipid profile test

The active drug, Metformin hydrochloride was a generous gift sample from Square Pharmaceuticals Ltd; Pabna, Bangladesh. Alloxan was purchased from Sisco Research Laboratories Pvt. Ltd. Mumbai, India. Serum triglycerides (TG) and total cholesterol (TC) concentrations were estimated by using wet reagent diagnostic kits purchased from Human Gesellschaft Company, Germany. All other chemicals and solvents were of analytical grade.

\section{Animal design (Figure 1)}

A total of 40 male Swiss Albino mice (weight, 20-25g) aged nine weeks were purchased from ICDDRB, Dhaka, Bangladesh and housed in animal cages under standard environmental conditions $\left(22-25^{\circ} \mathrm{C}\right.$, humidity $\left.60-70 \%\right)$ with water ad. libitum. The animals used in this study were cared according to guidelines of animal experiment. These 40 mice were divided into two experimental groups, each group with 20 mice. Two groups (20 $+20=40$ ) were studied for anti-hyperglycemic activity- one for short term and the other for a weeklong duration. Both of these groups were made diabetic by alloxan (alloxan is selectively toxic to insulin-producing pancreatic beta cells because it preferentially accumulates in beta cells through uptake via the GLUT2 glucose transporter). After 72 hours, blood glucose levels were measured from tail-vein blood of all groups by Glucometer considered as 0 min and blood glucose level higher than $11.5 \mathrm{mmol} / \mathrm{l}$ considered as diabetic. These alloxan induced two diabetic groups were investigated for a). a short term by OGTT $(\mathrm{n}=20)$ at $0,30,90$ and $120 \mathrm{~min}$; and $\mathrm{b})$ for a week-long anti-hyperglycemic activity $(\mathrm{n}=20)$ on day $0,1,3$ $\& 7$. Both the groups were subdivided into four, each having 5 mice - i) the 'control' received only $0.5 \%$ methyl cellulose as vehicle; ii) 'Standard' received vehicle plus metformin; iii \& iv) test DIA250 and DIA500 received vehicle plus IA extract with $250 \mathrm{mg}$ and $500 \mathrm{mg} / \mathrm{kg}$ b. wt., respectively. All blood samples were taken from tail-vein for estimation of blood glucose by glucometer. Lipid profile analysis was performed by estimating total cholesterol, triglyceride and glycogen concentration on 20 mice after a week-long anti-hyperglycemic tested mouse.

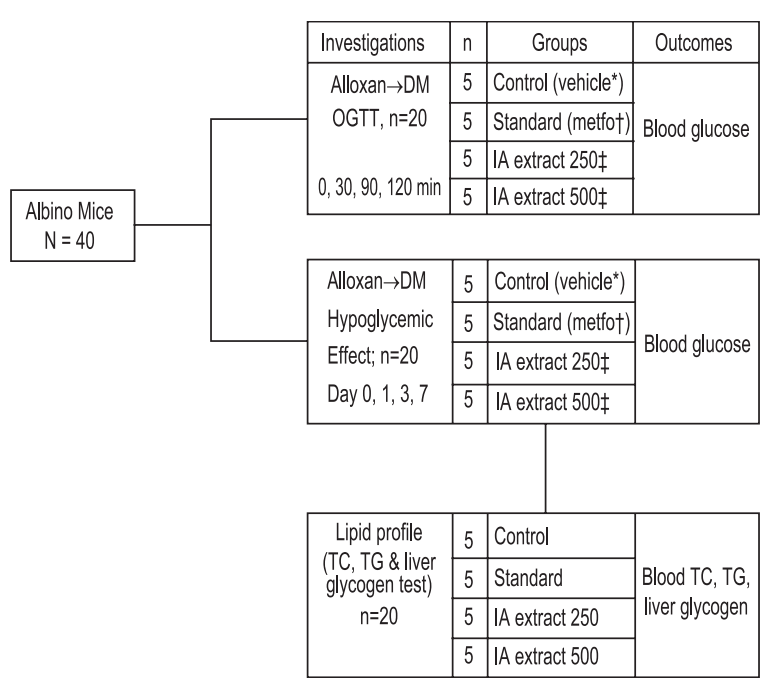

* - Vehicle $0.5 \%$ methyl cellulose given to all 4 groups, $\uparrow$ - Vehicle + metformin HCL ‡-vehicle + ethanolic extract of IA: Dose given orally (IA: 250 and $500 \mathrm{mg} / \mathrm{kg} \mathrm{b}$. wt),

Figure 1. Animal design

\section{Oral glucose tolerance test (OGTT)}

Short term test: one $\mathrm{ml}(50 \mathrm{mg} / \mathrm{ml})$ of glucose solution in a dose of $2 \mathrm{gm} / \mathrm{kg}$ body weight was administered to all groups by gastric tube. Simultaneously, one $\mathrm{ml} 0.5 \%$ methyl cellulose for the control (DC) and $1 \mathrm{ml}$ of $(2.5 \mathrm{mg} / \mathrm{ml}$ of $0.5 \%$ methyl cellulose) of standard drug metformin and one $\mathrm{ml}$ of extract was administered orally to group $250(6.25 \mathrm{mg} / \mathrm{ml})$ and 500 $(12.5 \mathrm{mg} / \mathrm{ml})$. The blood glucose content was measured after 30 mins, 90 mins and 120 mins.

\section{Anti-hyperglycemic test}

Weeklong test: Similarly, 20 mice were divided into four groups and each group comprised of five mice. One $\mathrm{ml}$ of $0.5 \%$ methyl cellulose, standard drug metformin and extract $(250 \mathrm{mg} / \mathrm{kg}$ and $500 \mathrm{mg} / \mathrm{kg}$ ) were administered once daily at 8:00 am for seven days to respective mice groups. Blood glucose content was measured before drug administration on $1^{\text {st }}, 3^{\text {rd }}$ and $7^{\text {th }}$ days.

Estimation of serum cholesterol and triglyceride in diabetic mice

After 7 days, completing blood glucose level estimation, mice were sacrificed and about $3 \mathrm{ml}$ of blood was collected directly from aorta of heart by syringe. Serum samples were obtained by centrifugation of blood (Centurion, UK) at $4000 \mathrm{rpm}$ for 10 minutes. The concentration of TC and TG were measured by UV-spectrophotometer (Shimadzu UV-1200, Tokyo, Japan), 
using wet reagent diagnostic kits according to the manufacturer's protocol.

Estimation of glycogen concentration in liver of diabetic mice The liver glycogen content was determined according to the method described by Tarnoky K. et. al ${ }^{12}$. Briefly, small portions of liver were extracted and treated with o-toluidine-glucose and after extraction coupling reaction was done with trichloroacetic acid (TCA) and precipitation by alcohol and hydrolysis. Finally, estimation of glycogen was performed by UV spectrophotometer.

\section{Phytochemical screening}

The freshly prepared leaf extract of GP was qualitatively tested for presence of chemical constituents. Phytochemical screening of GP extract was performed using following reagents and chemicals: Alkaloids with Mayer's, Hager's, and Dragendorffs reagent, Flavonoids with use of sodium acetate, ferric chloride, amyl alcohol; Phenolic compounds and tannins with lead acetate and gelatin; carbohydrate with Molish's, Fehling's and Benedict's reagent; proteins and amino acids with Millon's, Biuret, and xanthoprotein test. Saponin was tested using hemolysis method. These tests were identified by characteristic color changes using standard procedures Nayak and Pareira ${ }^{13}$.

\section{Statistical analysis}

The results were expressed as mean \pm SEM (Standard Error of Mean). Statistical analysis was performed by using ANOVA followed by Tukey's test using Graph pad Prism Software version 5.03 (Graph Pad Software, San Diego, CA, USA, www.graphpad.com). P values $<0.05$ were considered as statistically significant.

\section{Results}

\section{Antibacterial sensitivity effect}

Antibacterial effect of this extract has potent against Klebsiella aurogenosa compared with commercially available antibiotic of cetriaxone, ciprofloxacin and ampicillin (Figure 2). Results also showed antibacterial effect against Escherichia coli, Staphylococcus aureus, Bacillus cereus and Vibrio cholera (Figure 2).

Glucose tolerance effect of ethanol extract on diabetic mice

After oral administration of glucose, blood glucose levels were significantly higher in diabetic mice and results shown in Figure 2. In diabetic control the peak blood glucose level was observed after $30 \mathrm{~min}$ and remained high after next hour. Mice treated with extracts in groups DIA-250 and DIA-500 showed a significant decrease in blood glucose concentration 50.03\% and $66.09 \%$ respectively, at 120 min compared with diabetic control mice.

\section{Antidiabetic effect of ethanol extract in diabetic mice}

Hypoglycemic test when performed showed significant results compared with test group and control group. After 7 days of treatment with extract glucose levels were significantly lowered $57.89 \%$ and $69.12 \%$ using DIA-250 mg $/ \mathrm{kg}$ and DIA-500 mg/kg b. wt., respectively compared with diabetic control mice. This effect was found dose dependent (figure 3).

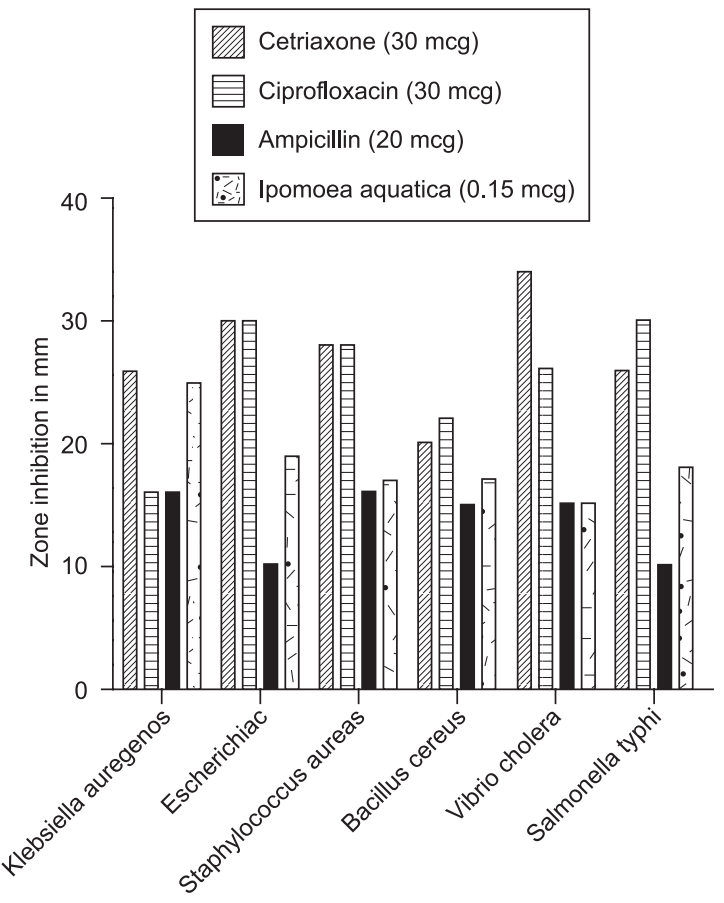

Figure 2. Comparartive study of antibacterial effect of IA with commercially available of antibiotics
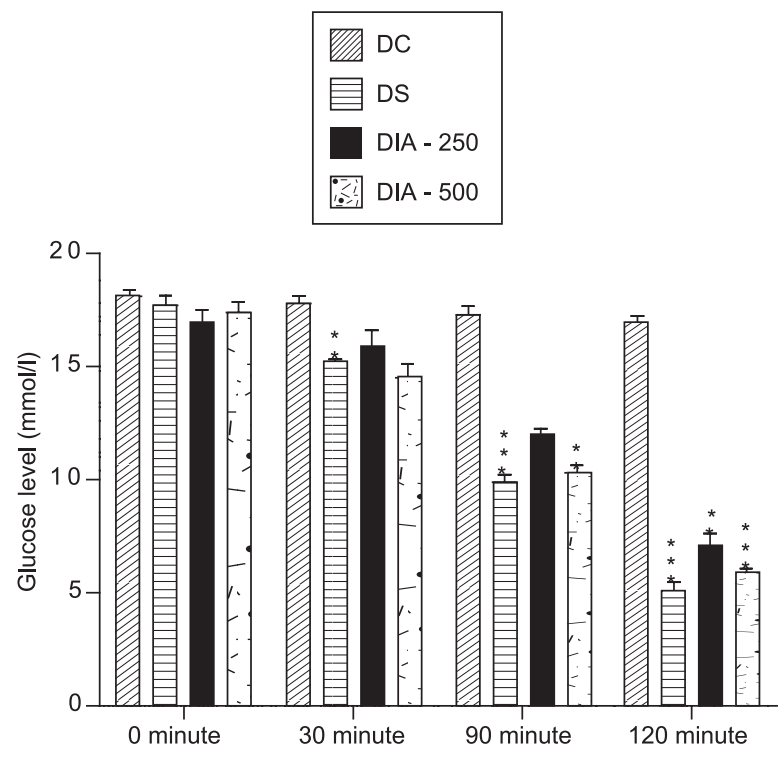

Figure 3. Glucose lowering effect of Ipomoea aquatica extract in diabetic mice. Values were expressed in Mean \pm SEM. Control group received 0.5\% Methyl cellulose and standard group received Metformin $100 \mathrm{mg} / \mathrm{kg}$. ${ }^{*} p<0.05$, $*^{* *} p<0.01$, and $* * * p<0.001$ indicate significant changes compared with diabetic control 
Effects of ethanolic extract on TC and TG level in diabetic mice

Comparison of liver lipid contents in diabetic control and experimental groups of mice are shown in figure 4 and 5 . A significant decrease $(p<0.05)$ in the levels of total cholesterol and triglycerides were observed in group DS, DIA-250 and DIA500 compared to diabetic control (DC) group. Administration of IA extract and metformin compared to diabetic control tends to bring to near normal level of TC and TG.

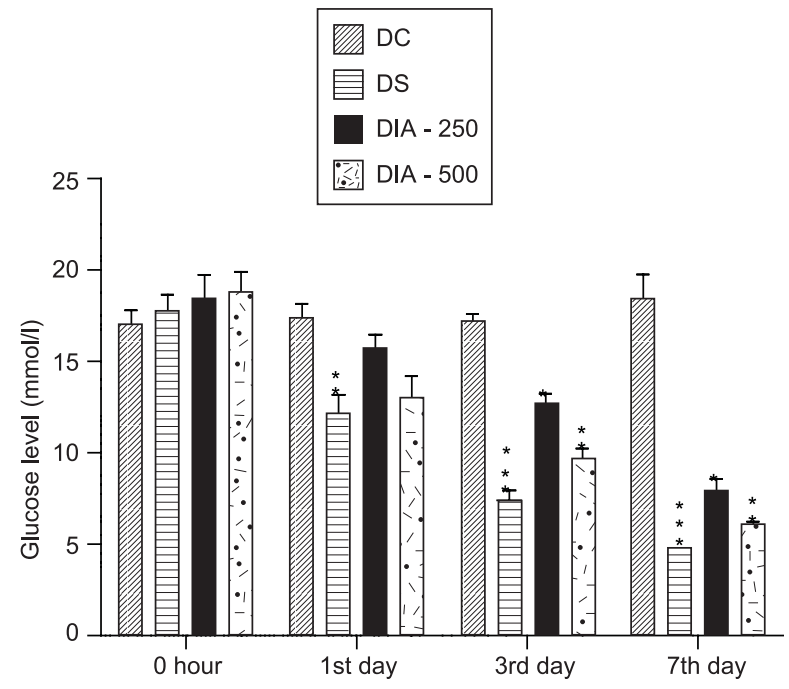

Figure 4. Antihyperglycemic effects of ethanol extract of IA compared to diabetic control. Values were expressed in Mean \pm SEM. Control group received 0.5\% Methyl cellulose and standard group received $100 \mathrm{mg} / \mathrm{kg}$ Metformin. ${ }^{*} p<0.05$, ${ }^{* *} p<0.01$, and $* * * p<0.001$ indicate significant changes compared with diabetic control

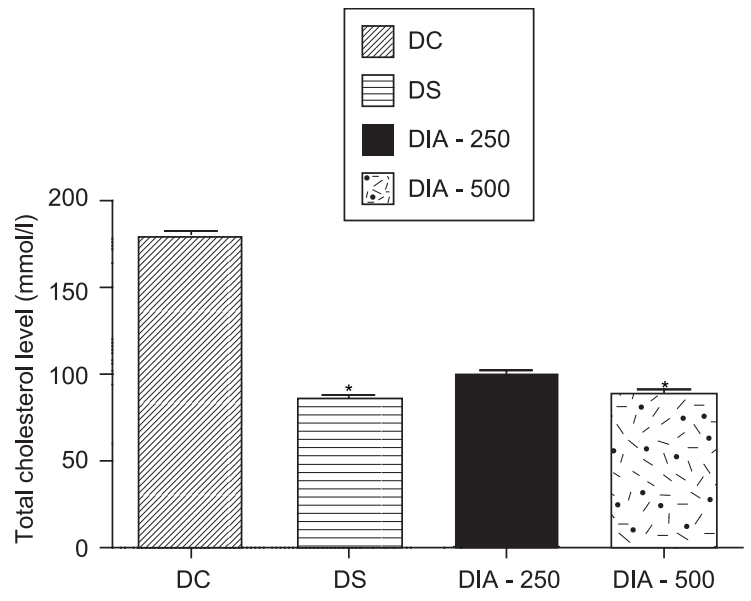

Figure 5. Effects of ethanolic extract of IA on the total cholesterol level. Values were expressed in Mean $\pm S E M .{ }^{*} p<0.05$ indicates significant changes compared with diabetic control
Effects of ethanolic extract on liver glycogen level in diabetic mice

In this study the level of glycogen in liver is increased in DS, DIA-250 and DIA-500 compared to diabetic control (DC) group. Treatment of diabetic mice with metformin and experimental groups significantly $(\mathrm{p}<0.05)$ improved the level of glycogen content compared to DC group as shown in figure 6.

Phytochemical screening test result of ethanolic extracts

Chemical constituents of alkaloids, protein, amino acids, phenol, flavonoids, saponin and tannin were found positive by chemical test of characteristic color changes. Carbohydrate gave negative result.

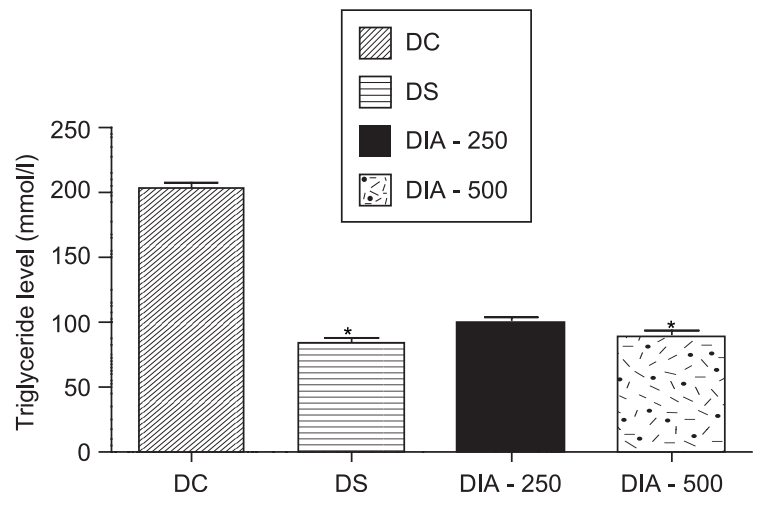

Figure 6. Effects of ethanol extract of IA on the triglyceride level. Values were expressed in Mean \pm SEM. ${ }^{*} p<0.05$ indicates significant changes compared with diabetic control

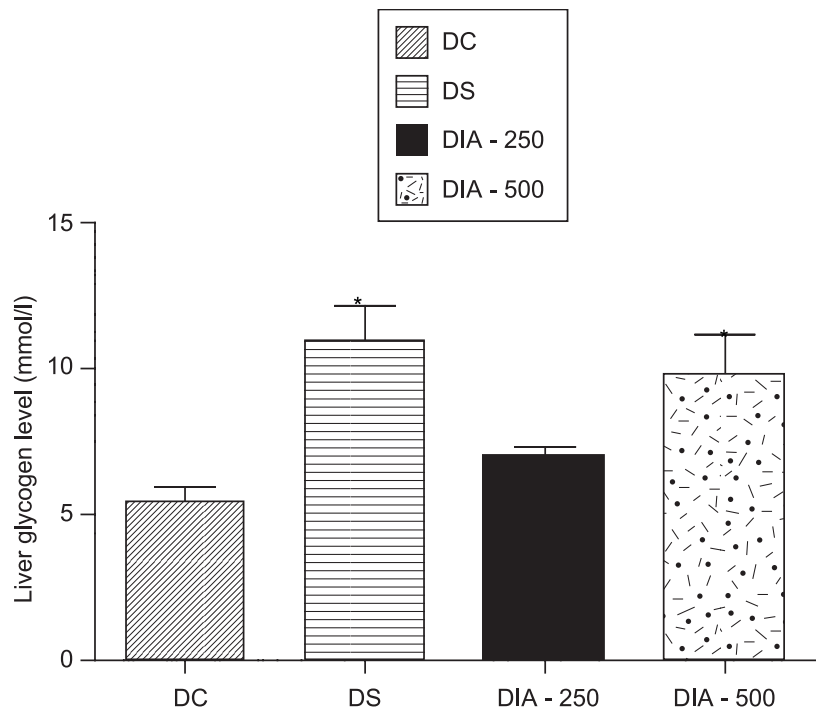

Figure 7. Effects of ethanol extract of IA on the liver glycogen level compared to diabetic control. Values were expressed in Mean \pm SEM. ${ }^{*} p<0.05$ indicates significant changes compared with diabetic control 


\section{Discussion}

Various parts of this plant has been used for traditional treatment of boils, fever, headache, insomia, laxative, piles, swelling, ulcer and wound. Recently, leafy vegetable are extensively investigated as a newer source of natural antioxidant and for other bioactive compounds of human health benefit ${ }^{14}$. Natural alternative treatments for bacterial infections may provide a pathway for the development of new antimicrobial agents. This study indicated that ethanolic extract was potent against both the grampositive and gram-negative bacteria shown in figure 2. The antibacterial efficacy of the leaf extract IA has been reported against four pathogenic bacterial strains $E$ coli, $P$ aeruginosa, $S$ aureus and $M$ luteus that indicated the extract has antibacterial property.

Traditional medicinal plants are used throughout the world for a wide range of diabetic management. The experiment showed that OGTT measures the body ability to use glucose; the body's main source of energy. In this experiment, extract IA showed a significant decrease in blood glucose concentration at $120 \mathrm{~min}$ compared with diabetic control mice (figure 3 ). The antihyperglycemic experiment for weeklong experiment also showed lower blood glucose level in figure 4. The effect on blood sugar levels were dose dependent. Extract may stimulate $ß$-cell for the secretion of insulin and are most effective for controlling diabetes due to presence of hypoglycemic alkaloid, saponin and flavonoid. The increase in the serum lipids on the diabetic subject is mainly due to the increased mobilization of free fatty acids from peripheral deposits, since insulin inhibits the hormone sensitive lipase ${ }^{15}$. Administration of ethanolic extract of IA showed significant reduction of serum lipid levels in mice such as triglyceride and total cholesterol (figure 5 \& 6). Flavonoids are known for their diverse activities including hypolipidemic and antioxidant activity ${ }^{16}$. IA extract contain flavonoids and related phenolic compounds. For this lipid lowering capacity of this plant extract, it may be proposed that the constituents of the plant extract may act as inhibitors for enzyme such as hydroxy-methyl-glutaryl-CoA reductase, which participates in de novo cholesterol biosynthesis ${ }^{17}$. Induction of diabetes with alloxan caused decrease in hepatic glycogen, which could be attributed to the decrease in the availability of the active form of enzyme glycogen synthetase probably because of low levels of insulin ${ }^{18}$. In the present study, IA restored the depressed hepatic glycogen levels possibly by increasing insulin (Figure 7 ). Decreased activities of the enzymes involved in glucose homeostasis in liver and kidney such as hexokinase has been reported in diabetic animal resulting in depletion of liver and muscle glycogen content ${ }^{19}$. Based on present study, the plant extract of Ipomoea aquatica possesses antibacterial, blood glucose and lipid lowering activities. However, further studies are needed to isolate active compounds responsible for these pharmacological activities and also necessary to examine underlying mechanism of antidiabetic and lipid lowering effects of Ipomoea aquatica

\section{References}

1. Westphal E. 1993. Ipomoea aquatica Forsk in Plant Resources in SouthEast Asia. Pudoc Scientific Publishers. 8:181-184.

2. Chen BH and ChenYY. 1992. Determination of carotenoids and chlorphylls in water convolvulus (Ipomoea aquatica) by liquid chromatography. Food Chemistry. 45:129-134.

3. Sunder Rao K, Dominic R, Sing K, Kaluwin C, Rivett DE and Jones GP. 1999. Lipid, fatty acid, amino acid and mineral composition of five edible plant lives. Journal of Argriculture and Food Chemistry. 38:1437-1441.

4. Tofen B, Mann P, Kaloga M, Jenett-Siems K, Wigge L and Eich E.1999 Aliphatic pyrrolidine amides from two tropical convolvulaceous. Phytochemistry. 52:1437-1441.

5. Van Valkenburg and Bunyapraphatsara N. 2001. Medicinal and poisonous Plants, Backhuys Publishers.

6. Wills RBH and Rangga A. 1996. Determination of carotenoids in Chinese vegitables. Food Chemestry. 56:451-455.

7. Badruzzaman and Hussain W. 1992. Some aquatic and marshy land medicinal plants from Hardoi district of Uttar Pradesh. Fitoterapia. 63(3):245-247.

8. Samuelsson G, Farah MH, Claeson P et al.1992. Inventory of plants used in traditional medicine in Somalia II. Plants of the familes Combretaceae to labiatat. J. Ethnopharmacol 37:47-70.

9. Malalavidhane TS, Wickramsinghe SMDN and Jansz ER. 2000. Oral hypoglycemic activity of Ipomoea aquatic. J Ethnopharmacol. 72:293298.

10. Duke JA and Ayensu ES. 1985. Medicinal Plants of china (Reference PUBl Algonac, ML).

11. Perry LM.1980. Medicinal plants of east and south-east Asia: Attributed properties and uses MIT press, Cambridge, MA.

12. Toronoky K et.al. 1963. "Spectrophotometric determination of glycogen with O-toludine”. Clin chim Acta. 38:627-628

13. Nayak BS and Pinto Pereira LM. 2006. Catharanthus roseus flower extract has wound-heating activity in Sprague Dawley rats. BMC Complement. and Alt.Medicine. 6(41):1-6.

14. Lakshmi B and Vimola V. 2000. Nutritive value of dehydrated green leafy vegetable. Journal of food Sci Technolog. 25:465-475.

15. Al-Shamaony L, Al- Khajraji SM, Tawaiji IA.1994. Hypoglycemic effect of Artemisia herba al II. Effect of a valuable extract on some blood parameters in diabetic animals. Journal of Ethnopharmacology. 43:167-171.

16. Afanas'ev IB, Ostrachovitch EA, Abramova NE and Korkina LG. 1995. Different antioxidant activities of biflavonoidrutin in normal and iron overloading rats. Biochem. Pharmacol. 80:627.

17. Bulbul J, Ullah MU, Rahman MA, Rahman KA, Paul AK and Chowdhurin MAK. 2009. Effect of Gharba Chintamani Rasa, an ayurvedic formulation on lipid profile, liver function and kidney function parameters of rat plasma chronic after administration. Europ, J. Sci. Res 32(1):26-32.

18. Rerup C. 1970. Drugs producing diabetes through damage of insulin secreting cells. Pharmacol Reviews. 22:485-520.

19. Vats V, Grover JK and Rathi SS. 2002. Evaluation of antihyperglycemic effect of Trigonella foemangracum, Ocimum sanctum and Pterocarpus marsupium in normal and alloxanized diabetic rats. Journal of Ethnopharmacology. 75:95-100. 